\title{
Establishing a Cancer Genetics Programme in Asia - the Singapore Experience
}

\author{
Wei-Shieng Chieng, Soo-Chin Lee \\ Department of Haematology-Oncology, National University Hospital, Singapore
}

Key words: cancer genetics, cancer genetics clinic, genetic testing, Asia

Corresponding author: Soo-Chin Lee, MD, Department of Haematology-Oncology, National University Hospital, 5 Lower Kent Ridge Road, Main Building Level 2, Singapore 119074, tel.: 6772-4621, e-mail: Soo_Chin_Lee@nuh.com.sg

Submitted: 29 May 2006

Accepted: 8 June 2006

\begin{abstract}
Cancer genetics is now an established oncology subspecialty with the primary prevention role of identifying high-risk individuals through genetic information for enrolment into screening and preventive programmes. Integrated into major Western centres since the late 1990s, such a programme has been established in Singapore since 2001. Our programme has evaluated 367 index patients comprising mainly breast and colorectal cancer cases. Cancer patients were receptive to genetic counselling, but cost posed a major barrier to genetic testing. However, when the cost barrier was removed through government subsidy plans, more than half of high-risk patients still declined testing. The major barriers were reluctance to involve family members, perception that the information would not change management, and fears of negative feelings. Confirmed mutation carriers were compliant to screening and receptive to prophylactic surgery. Uptake of predictive testing among cancer-free family members has been low, possibly arising from the stigma associated with cancer in our Asian culture. These potential barriers are being addressed through government subsidy plans, continuing education to increase awareness, and being culturally sensitive when dealing with the Asian family.
\end{abstract}

\section{Introduction}

About five to ten percent of all cancers are hereditary and due to germline mutations in cancer predisposition genes [1]. Advancements in molecular biology and genetics in the last 1-2 decades have enabled the cloning of key cancer predisposition genes, resulting in better characterization of major hereditary cancer syndromes. These include hereditary breast and ovarian cancer syndrome due to the BRCA $1 / 2$ genes [2, 3], hereditary non-polyposis colorectal cancer syndrome due to the mismatch repair genes [4-6], and familial adenomatous polyposis due to mutations in the APC gene [7]. The recognition of these syndromes and the establishment of management guidelines have led to the development of cancer genetics as a subspecialty in oncology [8-13]. Cancer genetics services have been incorporated into routine cancer services in major oncology centres in the West since the late 1990s. Such services represent an important primary prevention arm of oncology in its role of identifying high-risk individuals through family history assessment or genetic testing, and to enrol them into early cancer detection and prevention programmes, with the ultimate goal of reducing cancer burden and mortality.

Singapore is a small country of $699 \mathrm{~km}^{2}$ in South East Asia and home to 4 million people. Cancer is one of the major causes of mortality, and about 7800 cancer cases are diagnosed every year, with the leading 
cancers being lung, colorectal and breast cancers [14]. Health care in Singapore is provided through 9 public hospitals, 7 private hospitals, 16 government outpatient polyclinics, and some 1900 private medical clinics. Of the 9 public hospitals, two are tertiary hospitals that offer comprehensive cancer services, encompassing surgical, medical, and radiation oncology specialties. Cancer genetics services have been formally incorporated into the cancer services of both tertiary hospitals since 2001 .

Singapore is a multi-ethnic country comprising three major Asian ethnic populations: Chinese (77\%), Malay (14\%), and Indian (8\%). The Chinese and Indians are largely first- or second-generation migrants from China and Southern India, while the Malays are indigenous to the regions including Malaya, Sumatra, Java, and the other islands of the Indonesian archipelago. English is the official language, but Mandarin and Chinese dialects are the preferred languages used at home among $35 \%$ and $24 \%$ of Singaporeans respectively, followed by English (23\%), Malay (14\%) and Tamil (3\%). The average monthly household income in Singapore is $\$ \$ 4,943$ (US\$2,907), with $27 \%$ earning less than \$ \$1,999 (US\$1,176) [15].

Health cost is made affordable to the Singaporean public through government subsidized medical services at the public hospitals and outpatient government polyclinics through a co-payment system, where citizens pay a percentage of the medical bill, with the remainder subsidized by the government. This is aided by compulsory medical savings for every working adult, who contributes $6-8 \%$ of his or her monthly salary to a personal Medisave account that can be utilized to pay inpatient medical costs and outpatient cancer treatment.

\section{Cancer Genetics Programme at the National University Hospital, Singapore}

The cancer genetics programme at the National University Hospital, Singapore, is directed by a medical oncologist (SCL), who trained in cancer genetics at the John Hopkins University School of Medicine, USA, and was credentialed in 'Familial cancer risk assessment and management' by the Institute for Clinical Evaluation in the USA. The programme is assisted by a full-time cancer genetics counsellor (WSC), who is a graduate in Biomedical Science and who trained on the job.

The clinic receives patient referrals from specialists within the hospital and from other government hospitals, specialists practising in the private sector, as well as primary care physicians. The National University Hospital cancer service sees about 1500 new cancer cases every year, including approximately 600 new breast and colorectal cancers. Three-generation family cancer history forms are given routinely to all cancer patients at the hospital Cancer Centre. These forms are screened by the genetics counsellor to identify highrisk patients, such as those with young onset cancer, familial cancer clustering, and multiple primary cancers, who would warrant genetics risk assessment. High-risk cases are flagged to the primary cancer physician for referral to the cancer genetics programme.

The programme currently runs a weekly clinic, evaluating 1-5 patients per session. Patients who are referred from the government hospitals and polyclinics pay the subsidized rate of $S \$ 21$ (US\$12) for both first and follow-up visits. Patients who are self-referred, or referred by private hospitals and general practitioners, pay the full consultation fee of $\$ \$ 75$ (US $\$ 44$ ) and $\$ \$ 50$ (US\$29) for first and follow-up visits respectively.

The duration of each new case consultation is 45-60 minutes, while a typical follow-up visit lasts 15-20 minutes. Patients are evaluated and counselled individually or with their family members. During each new consultation, the patient's cancer and family histories are evaluated and an assessment made. Patients are classified as low, modest, moderate, or high risk of having a hereditary cancer syndrome, and are counselled accordingly. Patients assessed to be at low risk are given cancer screening recommendations pertaining to themselves and their family members based on their cancer and family history. Those assessed to have at least $10 \%$ chance of having a hereditary cancer syndrome are given genetic counselling for the particular syndrome [16], including the mode of inheritance, projected lifetime cancer risks, genetic testing including test interpretation and potential benefits and disadvantages of testing, and screening and preventive options [1]. The counselling session is conducted using picture aids, in English, Mandarin, a Chinese dialect, or Malay through an interpreter, according to the patient's preference. At the end of the session, a pamphlet in English or Mandarin summarizing the pertinent features of the hereditary cancer syndrome discussed is given to patients to facilitate retention of information. Pamphlets in Malay and Tamil are currently not available but may be developed in the future. Patients are given 1-2 weeks to assimilate and share the information with their family members. They are then followed up by a phone call or a separate clinic visit to address queries that may arise. 
Genetic testing that is offered through the programme includes BRCAl/2 comprehensive sequencing and single site mutation analysis for hereditary breast and ovarian cancer syndrome, MLHT/MSH2 comprehensive sequencing and single site mutation analysis and tumour microsatellite instability testing for hereditary non-polyposis colorectal cancer, APC protein truncation test for familial adenomatous polyposis, and sequencing of exons 10 , $11,13-16$ of the RET proto-oncogene for multiple endocrine neoplasias $2 A$ and $2 B[17,18]$. The latter three tests are offered by local laboratories, and cost S\$260-370 (US\$153-218) per test. BRCAl/2 and $\mathrm{MLHT} / \mathrm{MSH} 2$ comprehensive sequencing and respective single site mutation analysis are performed at Myriad Genetics Laboratories (Salt Lake City, Utah, USA) at the cost of $\$ \$ 5,058$ (US\$2,975), $\$ \$ 3,315$ (US\$1,950), and S\$595 (US\$350) respectively. Karyotyping for chromosomal abnormalities is offered locally, while genetic testing for rare conditions such as von Hippel Lindau syndrome and $\mathrm{E}$-cadherin gene analysis for hereditary diffuse gastric cancer syndrome [19] is performed in overseas laboratories. Costs for genetic testing are all out-of-pocket expenses as they are not subsidized by the Singapore government nor payable using Medisave. Since the initiation of the programme, colorectal cancer patients fulfilling eligibility criteria may opt to be tested for germline MLHT/MSH2 mutations free of charge as part of a research protocol. Since September 2003, patients assessed to have at least $30 \%$ chance of carrying a BRCAl/2 mutation are eligible to receive a $100 \%$ subsidy for BRCA1/2 sequencing, while their family members are eligible to a $50 \%$ subsidy for predictive testing through a special government subsidy programme.

Demographic information, cancer history, family history, genetic risk assessment information, screening recommendations, and genetic test results of patients evaluated in the cancer genetics programme are collected and stored in a user-defined and passwordprotected database.

\section{Results}

As cancer genetics is a new field in Singapore, we conducted a questionnaire survey in 2002 , shortly after we started the programme, to assess the level of knowledge on breast cancer risk factors and hereditary breast cancer syndrome. Among 284 health professionals and 221 medical students surveyed, less than a quarter recognized that paternal family history of cancer is as important as maternal family history in evaluating for hereditary breast cancer syndrome, and less than half were aware that genetic testing for hereditary breast cancer is clinically available, or that prophylactic mastectomy is a preventive option for women at high risk for breast cancer (Table 1) [20]. This general lack of awareness on emerging diagnostic and preventive options for hereditary breast cancer syndrome was identified as an important potential barrier to optimal utilization of the cancer genetics service, and active steps were taken to promote awareness through continuing medical education.

We next conducted a questionnaire survey to evaluate the acceptance and potential motivators and barriers of breast cancer genetic counselling among breast cancer patients and cancer-free women. About $70 \%$ of the 313 respondents indicated interest in attending genetic counselling when medically indicated and perceived the potential benefits. Higher education level among respondents was associated with greater acceptance of genetic counselling. Important motivators were learning about cancer risk and cancer detection,

Table 1. Awareness of breast cancer risk factors and genetics among health professionals and medical students $(n=505)$

\begin{tabular}{|c|c|c|c|c|}
\hline \multirow[b]{2}{*}{ Questionnaire items } & \multicolumn{4}{|c|}{ Percentage of correct response } \\
\hline & $\begin{array}{c}\text { doctors } \\
(n=124)\end{array}$ & $\begin{array}{c}\text { nurses } \\
(n=124)\end{array}$ & $\begin{array}{l}\text { paramedical staff } \\
\qquad(n=36)\end{array}$ & $\begin{array}{l}\text { medical students } \\
\qquad(n=221)\end{array}$ \\
\hline $\begin{array}{l}\text { to determine if a patient is at risk for hereditary breast cancer, } \\
\text { the maternal family history is more important than paternal family history }\end{array}$ & 22 & 19 & 27 & 20 \\
\hline $\begin{array}{l}\text { preventive mastectomy may reduce breast cancer risk } \\
\text { and may be recommended for women at high risk for breast cancer }{ }^{a}\end{array}$ & 55 & 31 & 35 & 44 \\
\hline $\begin{array}{l}\text { genetic testing for hereditary breast cancer through } \\
\text { a blood test is now clinically available }{ }^{a}\end{array}$ & 62 & 41 & 40 & 56 \\
\hline genetic breast cancer makes up $5-10 \%$ of all breast cancerb & 45 & 15 & 24 & 59 \\
\hline
\end{tabular}


Table 2. Acceptance, potential motivators and barriers of breast cancer genetic counselling among breast cancer patients and cancer-free women $(n=313)$

\begin{tabular}{lc}
\hline & Percentage \\
\hline Education level & willing to attend genetic counselling \\
$<10$ years formal education & 73 \\
10-12 years formal education & 82 \\
university/post-graduate & 92 \\
& $\mathrm{p}=0.024$ \\
\hline important motivators & $\%$ citing motivator as important \\
I can learn what to do to reduce my cancer risk & 91 \\
I want to know my cancer risk & 89 \\
I can learn what to do to detect cancer early & 89 \\
information may help my family understand their cancer risk & 86 \\
information may help my family make better health decisions & 85 \\
the doctor asked me to & 81 \\
\hline important barriers & $\%$ citing barrier as important \\
I already have cancer and it does not make a difference & $63^{\circ}$ \\
I am concerned about the cost & 58 \\
I do not like to hear bad news & 43 \\
I will not know what to do with the information & 42 \\
\hline
\end{tabular}

aresponses of breast cancer patients only

helping the family, and the doctor's recommendation. Important barriers were the misperception that cancer patients could not gain personally, cost issues, fears of bad news, and concerns of inability to make use of the information (Table 2) [21].

From January 2001 to March 2006, 367 new patients were evaluated at the cancer genetics clinic. $72 \%$ of referrals were from within the institution, while $28 \%$ were from other hospitals or clinics outside the institution. Patients with suspected hereditary breast cancer $(60 \%)$ and colorectal cancer syndromes (31\%) formed the majority of cases (Table 3). $87 \%$ of patients were assessed to have at least $10 \%$ chance of having a hereditary cancer syndrome and therefore offered genetic counselling and testing. Of these, $40 \%$ underwent genetic testing, and $23 \%$ of those tested were found to carry deleterious germline mutations (Table 4).

From July 2003, cancer patients and their accompanying family members were surveyed after the genetic counselling session (Table 5). The age distribution of the 110 cancer patients (median 37, range 23-77) and 95 cancer-free family members (median 39, range 16-65) surveyed were similar. Cancer-free family members who attended genetic counselling were more educated and more likely to express interest in genetic testing than cancer patients, with $81 \%$ indicating that they would definitely or probably take up genetic testing if medically indicated compared to $61 \%$ of cancer patients. For both groups, the most common motivators for genetic testing were to help their children and family members. Concerns about the cost of testing and belief that the information could not prevent another cancer were the most common reasons cited for not undertaking genetic testing. More than $80 \%$ of respondents indicated willingness to share genetic information with siblings and spouses, but only about $70 \%$ were willing to share the information with their parents. After the counselling session, 30\% and $22 \%$ of all respondents felt 'interested' and 'empowered or informed' respectively. Cancer patients were more likely to experience negative feelings after the session compared to cancer-free family members.

A total of 182 index patients were evaluated to have at least $10 \%$ chance of carrying a BRCA $1 / 2$ mutation and offered genetic testing. $48 \%$ were young onset breast cancer patients without significant family history, $38 \%$ were from breast cancer families, $12 \%$ were from breast-ovarian cancer families, and $2 \%$ were patients with male or bilateral breast cancers. 53/182 (29\%) eventually underwent BRCAT/2 comprehensive sequencing. There was no significant difference in ethnic group, age, and marital status between the acceptors and decliners. $28 \%$ of young breast cancer patients and $17 \%$ of patients from breast cancer families underwent testing, while $62 \%$ of index patients from breast-ovarian cancer families were tested. Seventeen patients (17/53, $32 \%$ ) were found to carry deleterious germline BRCA1/2 mutations. Family histories of breast or breast-ovarian cancer were the strongest predictors of finding a 
Table 3. Characteristics of patients reviewed in the cancer genetics clinic $(n=367)$

\begin{tabular}{|c|c|}
\hline age & \\
\hline median (range) & $39(17-80)$ \\
\hline \multicolumn{2}{|l|}{ ethnic group } \\
\hline Chinese & $78 \%$ \\
\hline Malay & $11 \%$ \\
\hline Indian & $4 \%$ \\
\hline others & $7 \%$ \\
\hline index patient has cancer & $74 \%$ \\
\hline \multicolumn{2}{|l|}{ risk categories } \\
\hline \multicolumn{2}{|l|}{ breast cancer-related cases $(n=219)$} \\
\hline low risk $(<10 \%)$ for hereditary breast cancer $(\mathrm{HBC})$ syndrome & $12 \%$ \\
\hline modest risk (10-20\%) for HBC syndrome & $65 \%$ \\
\hline moderate risk (20-40\%) for $\mathrm{HBC}$ syndrome & $11 \%$ \\
\hline high risk (>40\%) for HBC syndrome ${ }^{a}$ & $12 \%$ \\
\hline \multicolumn{2}{|l|}{ colorectal cancer-related cases $(n=114)$} \\
\hline low risk (<10\%) for hereditary colorectal cancer (HCRC) syndrome & $4 \%$ \\
\hline modest risk (10-20\%) for HCRC syndrome & $61 \%$ \\
\hline moderate risk (20-40\%) for HCRC syndrome & $24 \%$ \\
\hline high risk (>40\%) for HCRC syndrome ${ }^{b}$ & $11 \%$ \\
\hline \multicolumn{2}{|l|}{ others $(n=34)^{c}$} \\
\hline familial clustering of stomach cancers/young stomach cancers & $35 \%$ \\
\hline familial cancer clustering in a pattern not distinctive of known hereditary cancer syndromes & $30 \%$ \\
\hline others $^{d}$ & $35 \%$ \\
\hline
\end{tabular}

ainclude 10 patients counselled for predictive testing for a familial mutation; binclude 1 patient counselled for predictive testing for a familial mutation; c18 patients were deemed to have at least 10\% chance of having a known hereditary cancer syndrome and offered genetic counselling and testing; dfamilial clustering of or young nasopharyngeal cancers (9\%), familial clustering of renal cancers (9\%), suspected Li Fraumeni syndrome (6\%), familial clustering of paragangliomas suspicious of SDHD mutations (3\%), multiple endocrine neoplasia IIA (3\%), suspected neurofibromatosis (3\%), Turner's syndrome with young endometrial cancer (3\%)

deleterious mutation (Table 6). Of the 17 index patients found to carry BRCA7/2 mutations, five had bilateral mastectomy for breast cancers, and three had bilateral oophorectomy for ovarian cancer. Among the 12 carriers with intact breast(s), two (17\%) opted for prophylactic mastectomy, and two (17\%) are considering the option. Among the 14 carriers with intact ovaries, three $(21 \%)$ opted for prophylactic oophorectomy and three $(21 \%)$ are considering the option. Compliance to breast cancer screening with mammography among the high-risk breast cancer patients evaluated at the cancer genetics programme is $84 \%$, while that of BRCAT/2 mutation carriers is $94 \%$.

Twenty cancer-free family members were counselled for $B R C A T / 2$ predictive testing. Of these,
$55 \%$ were siblings and $25 \%$ adult children of the index patient, while the remaining were second- or thirddegree relatives (15\% nieces, $5 \%$ cousins). $67 \%$ of cancer-free family members who attended counselling for predictive testing were married, and 50\% had more than 10 years of formal education. Seven eventually underwent testing, of whom six (86\%) were found to carry deleterious mutations and are now on surveillance programmes. Two cancer-free mutation carriers are considering prophylactic surgery.

Sixty-six high-risk colorectal cancer patients were tested for MLH1/MSH2 mutations, predominantly as part of a research protocol free of charge. Nine mutation carriers (14\%) were identified. Fourteen family members had undergone predictive testing, and 6 were 
found to carry deleterious mutations and are on surveillance. None of the carriers had undergone prophylactic surgery. Factors that were associated with deleterious germline mutations include family history fulfilling Amsterdam I/II criteria (60\%), proband with early onset colorectal cancer and family history of colorectal cancer or extracolonic cancers (46\%), proband with colorectal cancer and family history of stomach cancer (40\%), and proband with colorectal cancer demonstrating high microsatellite instability (36\%) [22]. In contrast to what was reported in the West [23], family history of endometrial cancer predicted poorly for a deleterious mutation [22]. Compliance to screening colonoscopy among mutation carriers is $77 \%$.

Among the potential barriers uncovered through our previous hypothetical questionnaire survey, we found cost to be a major practical barrier to genetic testing. Prior to the initiation of the government subsidy programme for BRCA1/2 testing in 2003, 67/70 (96\%) breast cancer patients offered genetic testing declined the test, with the majority citing cost as a major barrier. After the initiation of the subsidy programme, 47/106 (44\%) eligible patients underwent BRCA1/2 testing at $100 \%$ government subsidy. However, 59/106 patients (56\%) still declined genetic testing despite removal of the cost barrier. A telephone survey of $39 / 59$ (66\%) patients who declined testing revealed the following major reasons: siblings/family members were not keen to know of such information or to be tested (41\%), perception that testing would not prevent cancer recurrence or alter medical management (39\%), and concerns about negative feelings associated with genetic test results (31\%) (Table 7).

\section{Discussion}

Cancer is a leading cause of morbidity and mortality in Singapore [14], and cancer genetics and risk assessment programmes represent the primary prevention arm of oncology. As a new programme in a mature comprehensive cancer centre, our current workload of approximately 75 new cases annually is close to the target 60-120 new referrals that are expected to arise from our institution. This has in part been attributed to our standard procedure to obtain family cancer history from each new cancer patient to identify high-risk patients for referral into the programme. In addition, the success of continuing medical education to increase awareness among physicians has been reflected by increasing referrals from outside the institution, now accounting for about $30 \%$ of our new cases.
Table 4. Genetic testing in Cancer Genetics Programme, National University Hospital, Singapore

\begin{tabular}{|c|c|}
\hline \multicolumn{2}{|l|}{ patients who underwent genetic testing $(n=127)$} \\
\hline test category & $\%$ \\
\hline BRCA1/2 comprehensive sequencing & 42 \\
\hline MLH1/MSH2 sequencing & 52 \\
\hline$A P C$ protein truncation test & 2 \\
\hline others $^{a}$ & 4 \\
\hline $\begin{array}{l}\text { patients with germline deleterious } \\
\text { mutation identified }(n=29)\end{array}$ & $\%$ \\
\hline BRCA1/2 mutation & 59 \\
\hline MLH1/MSH2 mutation & 31 \\
\hline APC mutation & 3 \\
\hline others $^{b}$ & 7 \\
\hline
\end{tabular}

aothers: comprehensive sequencing and rearrangement analysis for von Hippel Lindau (2), karyotyping for Turner's syndrome (1), sequencing for E-cadherin gene mutation (1), sequencing for SDHD gene mutation (1); bothers: Turner's syndrome (1), SDHD deleterious mutation (1)

In contrast to developed nations in the West, where lay press and lay media routinely report new medical advances and provide patients and community physicians easy access to new medical knowledge, health providers in Singapore generally rely on medical journals and seminars for information on medical advances, while patients rely on their health providers for pertinent medical information. Consequently it comes as no surprise to find only a handful of health providers in Singapore who are aware of BRCA $1 / 2$ genetic testing or prophylactic surgery for high-risk individuals. More importantly, lack of awareness of the mode of inheritance of the BRCA $1 / 2$ gene has led many health providers to have the mistaken notion that paternal family history is not as important as maternal family history in evaluating for hereditary breast cancer syndrome [20]. Such information has been critical for us to focus continuing medical education efforts on filling important knowledge gaps.

Cost has been cited as an important barrier to genetic counselling and testing in many prior studies, including our own [21, 24, 25]. While genetic counselling is available to Singaporeans at a subsidized and affordable rate, genetic testing is not. In fact, although a significant proportion of index patients expressed interest in BRCA $1 / 2$ testing, the uptake rate was a dismal $4 \%$ prior to 2003 when the cost of testing was not subsidized. This posed a significant barrier to downstream work of risk 
Table 5. Survey on genetic testing $(n=205)$

\begin{tabular}{|c|c|c|c|}
\hline \multirow[t]{2}{*}{ Category } & \multicolumn{3}{|c|}{ Percentage } \\
\hline & $\begin{array}{l}\text { cancer patients } \\
\quad(n=110)\end{array}$ & $\begin{array}{l}\text { cancer-free } \\
\text { family members } \\
(n=95)\end{array}$ & $\mathrm{p}$-value ${ }^{\mathrm{a}}$ \\
\hline breast cancer-related cases & 74 & 42 & 0.000 \\
\hline colorectal cancer-related cases & 23 & 57 & \\
\hline others & 3 & 1 & \\
\hline \multicolumn{4}{|l|}{ education level } \\
\hline$\leq 6$ years formal education & 11 & 5 & 0.036 \\
\hline 6-10 years formal education & 36 & 25 & \\
\hline$>10$ years formal education/diploma & 24 & 22 & \\
\hline university/ post-graduate degree & 29 & 48 & \\
\hline \multicolumn{4}{|c|}{ perception of likelihood of carrying genetic mutation } \\
\hline very certain of carrying mutation & 6 & 2 & 0.020 \\
\hline quite certain of carrying mutation & 36 & 19 & \\
\hline not sure & 39 & 52 & \\
\hline quite certain of not carrying mutation & 16 & 21 & \\
\hline very certain of not carrying mutation & 3 & 6 & \\
\hline \multicolumn{4}{|l|}{ taking genetic test if medically indicated? } \\
\hline yes definitely & 33 & 53 & 0.004 \\
\hline yes probably & 28 & 28 & \\
\hline not sure & 20 & 15 & \\
\hline no probably & 8 & 1 & \\
\hline no, not at all & 11 & 3 & \\
\hline \multicolumn{4}{|l|}{ reasons for undergoing genetic testing ${ }^{b}$} \\
\hline beneficial to children & 60 & 58 & 0.777 \\
\hline beneficial to family members & 51 & 43 & 0.326 \\
\hline understand my cancer risk & 16 & 38 & 0.000 \\
\hline motivates me to go for cancer screening & 18 & 34 & 0.015 \\
\hline \multicolumn{4}{|l|}{ reasons against genetic testing $b$} \\
\hline $\cos t$ & 21 & 8 & 0.018 \\
\hline can't prevent another cancer & 12 & 11 & 0.827 \\
\hline may feel depressed/angry/upset/stressed & 9 & 7 & 0.801 \\
\hline worried about feelings of family & 8 & 5 & 0.580 \\
\hline worried about insurability & 5 & 7 & 0.553 \\
\hline \multicolumn{4}{|l|}{ will share information with } \\
\hline parents & 68 & 76 & 0.278 \\
\hline siblings & 87 & 95 & 0.090 \\
\hline children & 66 & 72 & 0.447 \\
\hline spouse & 82 & 82 & 1.000 \\
\hline \multicolumn{4}{|l|}{ feelings after genetic counsellingc } \\
\hline negative feelings $^{d}$ & $40^{\mathrm{e}}$ & $24^{f}$ & 0.018 \\
\hline indifferent & 29 & 14 & 0.011 \\
\hline interested & 26 & 35 & 0.169 \\
\hline empowered/informed & 19 & 24 & 0.398 \\
\hline relieved/satisfied & 12 & 23 & 0.040 \\
\hline
\end{tabular}

astatistical analysis was performed using Chi-square test for categorical variables, and Student's t-test for age; brespondents were allowed to cite more than one reason; crespondents may describe more than one kind of feelings; drespondents may describe more than one kind of negative feelings; enegative feelings: anxious

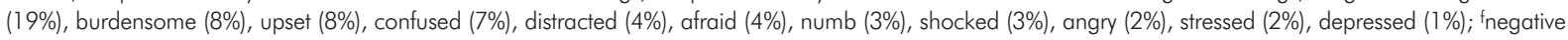
feelings: anxious (13\%), afraid (5\%), confused (4\%), upset (4\%), stressed (4\%), burdensome (3\%), depressed (3\%), distracted (3\%), numb (1\%) 
segregating individuals and tailoring screening and preventive recommendations using genetic testing. Under the special government subsidy programme that provided free BRCA1/2 testing for index patients, we observed an eleven-fold increase in genetic testing uptake rate to $44 \%$, allowing mutation carriers to be identified and facilitating predictive testing in cancer-free family members. This highlights the importance of overcoming cost as a barrier to allow the full realization of the potential of a cancer genetics programme.

Despite removing the cost barrier, we found more than half of eligible patients to still decline genetic testing, suggesting that other barriers exist. A survey on the decliners revealed a striking reluctance to involve family members. The central role of the family in Asian culture is underscored by the fact that more than $80 \%$ of respondents in a hypothetical situation [21], and more than $50 \%$ of high-risk patients who underwent genetic counselling in our population, cited 'helping the family' to be an important motivator to attend genetic counselling and undertake genetic testing respectively. Yet, when it comes to actual genetic testing and the real possibility of involving family members for predictive testing, two-fifths of decliners cited 'siblings/family members not keen' to be the reason. Even among families with deleterious BRCA1/2 mutations, fewer than 2 family members per index patient have attended genetic counselling, and less than 1 family member per index patient has opted for predictive testing, highlighting the complexity of involving cancer-free family members in cancer predisposition testing. This low uptake in predictive testing has similarly been reported both in the West and in Asia [26, 27]. It was also noteworthy that while over $80 \%$ of patients counselled were willing to share genetic information with spouses and siblings, only about $70 \%$ were willing to involve the older generation such as their parents. These behaviours may stem from traditional Asian beliefs that cancer is a curse that is associated with a stigma and therefore shameful to discuss, causing some cancer patients to be unwilling to broach the subject with cancer-free family members. Cancer is also viewed as a taboo in traditional Chinese beliefs, and many may feel that discussing it freely in the family or testing for cancer predisposition constitutes bad luck [28-31]. Indeed, one-third of patients described 'negative feelings' after receiving genetic counselling, and about $30 \%$ of high-risk breast cancer patients who declined genetic testing were worried about 'negative feelings' that the test results may incite. These concerns may be amplified in our traditional Asian society [32].
Table 6. Nature of $B R C A 7 / 2$ deleterious mutations and factors associated with deleterious $B R C A 7 / 2$ mutation $(n=17)$

\begin{tabular}{|c|c|}
\hline & Percentage \\
\hline \multicolumn{2}{|l|}{ nature of deleterious mutation } \\
\hline frameshift & 59 \\
\hline nonsense & 23 \\
\hline large deletions/rearrangements & 18 \\
\hline \multicolumn{2}{|c|}{$\begin{array}{l}\text { probability of identifying deleterious } B R C A 1 / 2 \text { mutation based } \\
\text { on risk profile }\end{array}$} \\
\hline $\begin{array}{l}\text { cancer patient with family history of breast } \\
\text { and ovarian cancer }(n=13)\end{array}$ & 54 \\
\hline $\begin{array}{l}\text { cancer patient with family history of breast cancer } \\
(\mathrm{n}=12)\end{array}$ & 50 \\
\hline $\begin{array}{l}\text { young onset breast cancer without family history } \\
\text { of cancer }(n=25)\end{array}$ & 16 \\
\hline male breast cancer/bilateral breast cancer $(n=3)$ & 0 \\
\hline
\end{tabular}

Table 7. Demographic characteristics of index patients who declined $B R C A 7 / 2$ testing despite test cost subsidies and reasons for declining $(n=39)$

\begin{tabular}{|c|c|}
\hline median (range) & $36(23-77)$ \\
\hline married & $80 \%$ \\
\hline \multicolumn{2}{|l|}{ educational level } \\
\hline$\leq 6$ years formal education & $20 \%$ \\
\hline 6-10 years formal education & $23 \%$ \\
\hline$>10$ years formal education/diploma & $30 \%$ \\
\hline university/post-graduate degree & $27 \%$ \\
\hline \multicolumn{2}{|l|}{ reasons for declining genetic testing ${ }^{a}$} \\
\hline siblings/family members not keen & $41 \%$ \\
\hline $\begin{array}{l}\text { doing this test would not prevent } \\
\text { recurrence/change anything much }\end{array}$ & $39 \%$ \\
\hline $\begin{array}{l}\text { fear of negative feelings associated with knowing } \\
\text { genetic test results }\end{array}$ & $31 \%$ \\
\hline worried about feelings of family & $13 \%$ \\
\hline worried about insurance/employability & $10 \%$ \\
\hline $50 \%$ subsidy for predictive testing is still a barrier ${ }^{b}$ & $8 \%$ \\
\hline $\begin{array}{l}\text { sceptical about modern medicine such } \\
\text { as genetic testing }\end{array}$ & $3 \%$ \\
\hline
\end{tabular}

apatients were allowed to indicate more than one reason for declining test; ${ }^{b}$ cost of single site mutation analysis in predictive testing is $\$ \$ 595$ (US\$350) and the Singapore government provides $50 \%$ reimbursement 
The low uptake of predictive testing is contrary to our survey finding of high interest in genetic testing among cancer-free family members who attended genetic counselling. One reason could be that family members needed more time to decide on predictive testing, since many index patients had only been confirmed to carry mutations in the last 2-3 years [24]. Another reason for this discrepancy is the possibility that cancer-free family members who attended genetic counselling represent a select and more healthconscious population, but who may ultimately not have access to genetic testing because the index patient opted not to be tested or was not found to carry a mutation. In addition, while many family members may express interest in the hypothetical situation, when faced with the real prospect of genetic testing, they may ultimately decline testing because of the fear of being labelled a gene carrier in a traditional society that views cancer as a stigma [32].

We found encouragingly high cancer screening compliance rates among the high-risk breast and colorectal cancer patients in our programme, while the uptake rate for prophylactic surgery among BRCA $1 / 2$ mutation carriers is comparable to those reported in other centres [33,34], with $47 \%$ of carriers undergoing or contemplating prophylactic mastectomy and/or oophorectomy in our programme.

\section{Conclusion}

Singapore is a developed nation with a comprehensive public healthcare system, and we have successfully initiated a cancer genetics programme in the context of a tertiary hospital. By increasing awareness and level of knowledge among health providers in Singapore, we hope to extend the programme to the community in the future. Certain elements unique to Singapore could enhance the success of our programme, including easy access to medical records and family members, affordable health screening services, and good doctor-patient relationships. At the same time, we have identified potential barriers that are actively being addressed. These include overcoming the cost issue of genetic testing through government assistance plans or health policy changes, continuing medical and public education to increase awareness and knowledge, and being culturally sensitive when dealing with the subject of cancer and cancer predisposition testing with the Asian family. Complex medical, social, ethical and legal aspects surround genetic testing, and we hope in the future to integrate other specialists, such as surgeons, psychiatrists, and social workers into a more comprehensive programme.

\section{Acknowledgements}

We thank Ms May-Chin Yong and Ms Robyn Yip for assisting in genetic counselling and data collection at the cancer genetics clinic.

\section{References}

1. ASCO curriculum: Cancer genetics and cancer predisposition testing - Breast and Ovarian Cancer. Vol II; 1998.

2. Miki Y, Swensen J, Shattuck-Eidens D, Futreal PA, Harshman K, Tavtigian S, Liu Q, Cochran C, Bennett LM, Ding W, et al. A strong candidate for the breast and ovarian cancer susceptibility gene BRCA1. Science 1994; 266: 66-71

3. Wooster R, Neuhausen SL, Mangion J, Quirk Y, Ford D, Collins N, Nguyen K, Seal S, Tran T, Averill D, et al. Localization of a breast cancer susceptibility gene, BRCA2, to chromosome 13q12-13. Science 1994; 265: 2088-2090.

4. Peltomaki P, Aaltonen LA, Sistonen P, Pylkkanen L, Mecklin JP, Jarvinen H, Green JS, Jass JR, Weber JL, Leach FS, et al. Genetic mapping of a locus predisposing to human colorectal cancer [see comments]. Science 1993; 260: 810-812.

5. Papadopoulos $\mathrm{N}$ and Lindblom A. Molecular basis of HNPCC: mutations of MMR genes. Hum Mutat 1997; 10: 89-99.

6. Miyaki M, Konishi M, Tanaka K, Kikuchi-Yanoshita R, Muraoka M, Yasuno M, Igari T, Koike M, Chiba M and Mori T. Germline mutation of MSH6 as the cause of hereditary nonpolyposis colorectal cancer [letter]. Nat Genet 1997; 17: 271-272.

7. Powell SM, Petersen GM, Krush AJ, Booker S, Jen J, Giardiello FM, Hamilton SR, Vogelstein B and Kinzler KW. Molecular diagnosis of familial adenomatous polyposis. N Engl J Med 1993; 329: 1982-1987.

8. Burke W, Petersen G, Lynch P, Botkin J, Daly M, Garber J, Kahn MJ, McTiernan A, Offit K, Thomson E and Varricchio C. Recommendations for follow-up care of individuals with an inherited predisposition to cancer. I. Hereditary nonpolyposis colon cancer. Cancer Genetics Studies Consortium. JAMA 1997; 277: 915-919.

9. Burke W, Daly M, Garber J, Botkin J, Kahn MJ, Lynch P, McTiernan A, Offit K, Perlman J, Petersen G, Thomson E and Varricchio C. Recommendations for follow-up care of individuals with an inherited predisposition to cancer. II. BRCA1 and BRCA2. Cancer Genetics Studies Consortium [see comments]. JAMA 1997; 277: 997-1003.

10. Jarvinen HJ, Aarnio M, Mustonen H, Aktan-Collan K, Aaltonen LA, Peltomaki P, De La Chapelle A and Mecklin JP. Controlled 15-year trial on screening for colorectal cancer in families with hereditary nonpolyposis colorectal cancer [see comments]. Gastroenterology 2000; 118: 829-834.

11. Meijers-Heijboer $H$, van Geel B, van Putten WL, HenzenLogmans SC, Seynaeve C, Menke-Pluymers MB, Bartels CC, Verhoog LC, van den Ouweland AM, Niermeijer MF, Brekelmans CT and Klijn JG. Breast cancer after prophylactic bilateral mastectomy in women with a BRCA1 or BRCA2 mutation. N Engl J Med 2001; 345: 159-164.

12. Rebbeck TR, Lynch HT, Neuhausen SL, Narod SA, Van't Veer L, Garber JE, Evans G, Isaacs C, Daly MB, Matloff E, Olopade OI and Weber BL. Prophylactic oophorectomy in carriers of BRCA1 or BRCA2 mutations. N Engl J Med 2002; 346: 1616-1622.

13. Schmeler KM, Lynch HT, Chen LM, Munsell MF, Soliman PT, Clark MB, Daniels MS, White KG, Boyd-Rogers SG, Conrad PG, Yang 
KY, Rubin MM, Sun CC, Slomovitz BM, Gershenson DM and Lu $\mathrm{KH}$. Prophylactic surgery to reduce the risk of gynecologic cancers in the Lynch syndrome. N Engl J Med 2006; 354: 261-269.

14. Seow A, Koh WP, Chia KS, Shi LM, Lee HP and Shanmugaratnam K. Trends in Cancer Incidence in Singapore 1968-2002. Singapore Cancer Registry Report No. 6. 2004.

15. Singapore-Statistics-Department. Census of Population 2000. 2000: 4.

16. American Society of Clinical Oncology policy statement update: genetic testing for cancer susceptibility. J Clin Oncol 2003; 21: 2397-2406.

17. Ledger GA, Khosla S, Lindor NM, Thibodeau SN and Gharib H. Genetic testing in the diagnosis and management of multiple endocrine neoplasia type II. Ann Intern Med 1995; 122: 118-124.

18. Chiefari E, Russo D, Giuffrida D, Zampa GA, Meringolo D, Arturi F, Chiodini I, Bianchi D, Attard M, Trischitta V, Bruno R, Giannasio P, Pontecorvi A and Filetti $S$. Analysis of RET protooncogene abnormalities in patients with MEN 2A, MEN 2B, familial or sporadic medullary thyroid carcinoma. J Endocrinol Invest 1998; 21: 358-364.

19. Brooks-Wilson AR, Kaurah P, Suriano G, Leach S, Senz J, Grehan N, Butterfield YS, Jeyes J, Schinas J, Bacani J, Kelsey M, Ferreira P, MacGillivray B, MacLeod P, Micek M, Ford J, Foulkes W, Australie K, Greenberg C, LaPointe M, Gilpin C, Nikkel S, Gilchrist D, Hughes R, Jackson CE, Monaghan KG, Oliveira MJ, Seruca R, Gallinger S, Caldas C and Huntsman D. Germline E-cadherin mutations in hereditary diffuse gastric cancer: assessment of 42 new families and review of genetic screening criteria. J Med Genet 2004; 41: 508-517.

20. Yong MC, Zhou XJ and Lee SC. The importance of paternal family history in hereditary breast cancer is underappreciated by health care professionals. Oncology 2003; 64: 220-226.

21. Chin TM, Tan SH, Lim SE, lau P, Yong WP, Wong SW and Lee SC. Acceptance, motivators, and barriers in attending breast cancer genetic counselling in Asians. Cancer Detect Prev 2005; 29: $412-418$

22. Lee SC, Guo JY, Lim R, Soo R, Koay E, Salto-Tellez M, Leong A and Goh BC. Clinical and molecular characteristics of hereditary non-polyposis colorectal cancer families in Southeast Asia. Clin Genet 2005; 68: 137-145.

23. Aarnio M, Mecklin JP, Aaltonen LA, Nystrom-Lahti M and Jarvinen $\mathrm{HJ}$. Life-time risk of different cancers in hereditary nonpolyposis colorectal cancer (HNPCC) syndrome. Int J Cancer 1995; 64: 430-433

24. Lee SC, Bernhardt BA and Helzlsover KJ. Utilization of BRCA1/2 genetic testing in the clinical setting: report from a single institution. Cancer 2002; 94: 1876-1885.

25. Durfy SJ, Bowen DJ, McTiernan A, Sporleder J and Burke W. Attitudes and interest in genetic testing for breast and ovarian cancer susceptibility in diverse groups of women in western Washington. Cancer Epidemiol Biomarkers Prev 1999; 8: 369-375.

26. Landsbergen $K$, Verhaak $C$, Kraaimaat $F$ and Hoogerbrugge $N$. Genetic uptake in BRCA-mutation families is related to emotional and behavioral communication characteristics of index patients. Fam Cancer 2005; 4: 115-119.

27. Rajkumar T, Soumittra N, Vidubula E, Sridevi V, Mahajan V, Ramanan SG and Vijaya $S$. Organization and running of the first comprehensive hereditary cancer clinic in India. Hereditary Cancer in Clinical Practice 2005; 3: 165-170.

28. Glanz K, Grove J, Lerman C, Gotay C and Le Marchand L. Correlates of intentions to obtain genetic counselling and colorectal cancer gene testing among at-risk relatives from three ethnic groups. Cancer Epidemiol Biomarkers Prev 1999; 8: 329-336.

29. Eisenbruch M, Yeo SS, Meiser B, Goldstein D, Tucker K and Barlow-Stewart K. Optimising clinical practice in cancer genetics with cultural competence: lessons to be learned from ethnographic research with Chinese-Australians. Soc Sci Med 2004; 59: 235-248

30. Huang X, Butow P, Meiser B and Goldstein D. Attitudes and information needs of Chinese migrant cancer patients and their relatives. Aust N Z J Med 1999; 29: 207-213.

31. Benowitz $S$. To tell the truth: a cancer diagnosis in other cultures is often a family affair. J Natl Cancer Inst 1999; 91: 1918-1919.

32. Westbrook MT, Legge $V$ and Pennay M. Attitudes towards disabilities in a multicultural society. Soc Sci Med 1993; 36: 615-623.

33. Wainberg $S$ and Husted J. Utilization of screening and preventive surgery among unaffected carriers of a BRCA1 or BRCA2 gene mutation. Cancer Epidemiol Biomarkers Prev 2004; 13: 1989 1995.

34. Metcalfe KA, Snyder C, Seidel J, Hanna D, Lynch HT and Narod S. The use of preventive measures among healthy women who carry a BRCA1 or BRCA2 mutation. Fam Cancer 2005; 4: 97-103. 